\title{
İleusa Neden Olan İnce Barsak Divertikülü: Olgu Sunumu
}

\author{
A Small Intestinal Diverticule Resulting in Ileus
}

Faruk PEHLİVANLI' ${ }^{1}$, Sahil EVCIMEN', Oktay AYDIN² ${ }^{2}$,ökhan KARACA ${ }^{3}$

${ }^{1}$ Kırıkkale Yüksek Ihtisas Devlet Hastanesi Genel Cerrahi Bölümü, KIRIKKALE

${ }^{2}$ Gaziantep Dr. Ersin Arslan Devlet Hastanesi Genel Cerrahi Kliniği, GAZİANTEP

${ }^{3}$ Kırlkkale Üniversitesi Genel Cerrahi A.D., KIRIKKALE

\begin{abstract}
ÖZET
İnce barsak divertikülleri genellikle asemptomatik olup çok nadir görülürler. $\mathrm{Bu}$ nedenle tanıları genellikle operasyonlarda tesadüfen konulmaktadır. Bulantı, kusma, karın ağrısı gibi nonspesifik semptomlar da oluşturabilen bu divertiküller, nadiren ileus, gastrointestinal kanama, perforasyon, divertikülit gibi ciddi komplikasyonlara da neden olabilmektedirler. Jejunoileal divertiküllerin yol açabileceği nonspesifik semptomlar ve ciddi akut komplikasyonlar akılda tutulduğu takdirde erken tanı konulabilir ve bu divertiküllere bağlı morbidite ve mortalite oranları düşürülebilir. $\mathrm{Bu}$ yazıda üç gündür devam eden akut başlangıçlı karın ağrısı olan ve obstrüksiyona neden olan ince barsak divertikülü saptanan acil olgu tartışılmıştır.
\end{abstract}

Anahtar Kelimeler: Ileus, ince barsak divertikülü

\section{GİRIS}

Meckel divertikülleri dışındaki incebarsak divertikülleri oldukça nadir olup genel populasyonda \%0.06-1,9 oranında görülmektedir (1). Sıklıkla semptom vermeyen bu divertiküller, nonspesifik kronik semptomlar da oluşturabilirler. Ayrıca nadiren kanama, divertikülit, perforasyon, ileus gibi akut ve ciddi komplikasyonlara da neden olabilirler (2).

\begin{abstract}
Small intestinal diverticula are seldom seen and are usually asymptomatic. Therefore they are usually diagnosed incidentally during laparotomies. Nausea, vomiting, abdominal pain are nonspecific symptoms seen in these diverticula while severe complications like ileus, gastrointestinal bleeding, perforation and diverticulitis can also be encountered. If these nonspecific symptoms and severe acute complications are kept in mind, jejunoileal diverticula can be diagnosed early leading to a reduction in morbidity and mortailty rates. In the case, a small intestinal diverticule presenting with an acute onset abdominal pain and obstruction of three days is discussed.
\end{abstract}

Keywords: Ileus, small intestinal diverticula

İncebarsak divertiküllerinin perforasyonu veya ileusa neden olması durumunda mortalite oranları \%40'lara ulaşmaktadır. $\mathrm{Bu}$ olguda ileusa neden olan bir jejunoileal divertikülü tartışılmıştır. 


\section{OLGU}

Son üç gündür devam eden karın ağrısı, gaz gaita çıkaramama ve kusma şikâyetleri olan 56 yaşındaki kadın hasta dahiliye polikliniğine başvurdu. Hastanın soygeçmişinde bir özellik yoktu. Özgeçmişinde sol meme kanseri nedeniyle modifiye radikal mastektomi yapıldığı ve 10 yıldır diabetes mellitus tanısı olduğu öğrenildi. Fizik muayenede batında yaygın hassasiyet, distansiyon ve rebound vard1. Rektal tuşede özellik yoktu. Kan basinc1 120/65 mmHg, solunum sayıs1 24/dk, nabız sayısı 90/dk, ateş: $37,2^{\circ} \mathrm{C}$ olarak ölçüldü. Yapılan laboratuvar incelemelerinde lökosit $14800 / \mathrm{mm}^{3}$, kan üre azotu $54 \mathrm{mg} / \mathrm{dl}$, kreatinin 0,9 mg/dl, kan şekeri:215mg/dl idi. Direkt karın grafisinde ince barsak düzeyinde hava sıvı seviyeleri mevcuttu. Yapılan bilgisayarlı tomografide aşırı ödemli ve distandü olan barsak ansları görüldü (Resim 1). Yapılan fizik muayene ve laboratuvar testleri sonucunda hasta akut karın tanısı ile acil olarak ameliyata alındı. Eksplorasyonda Treitz ligamentinden yaklaşık $150 \mathrm{~cm}$ mesafede yaklaşık $3 \mathrm{~cm}$ boyutlarındaki divertikülün sağ pelvik duvara yapıştığ ve intestinal obstrüksiyon yaptığı görüldü (Resim 2). Hastaya bridektomi ve nekroze olan divertikülü içine alan yaklaşık 5-6 cm'lik ince barsak rezeksiyonu ile uç uca anostomoz yapıldı. Hasta postoperatif dönemde 2 gün yoğun bakımda tutulduktan sonra postoperatif 9.gün şifa ile taburcu edildi.

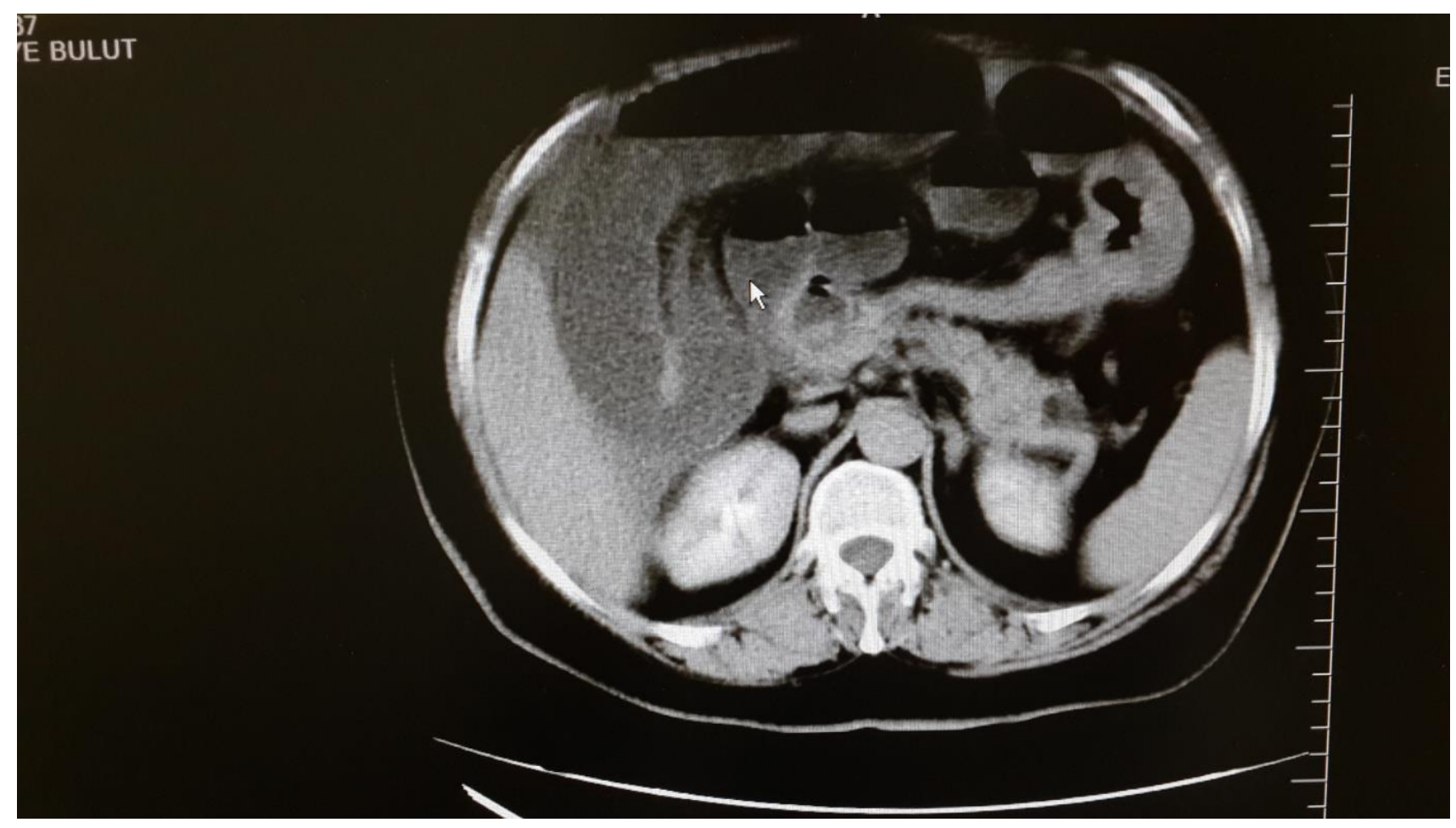

Resim 1: Abdominal tomografide ince barsaklardaki ödem ve barsak seviyeleri 


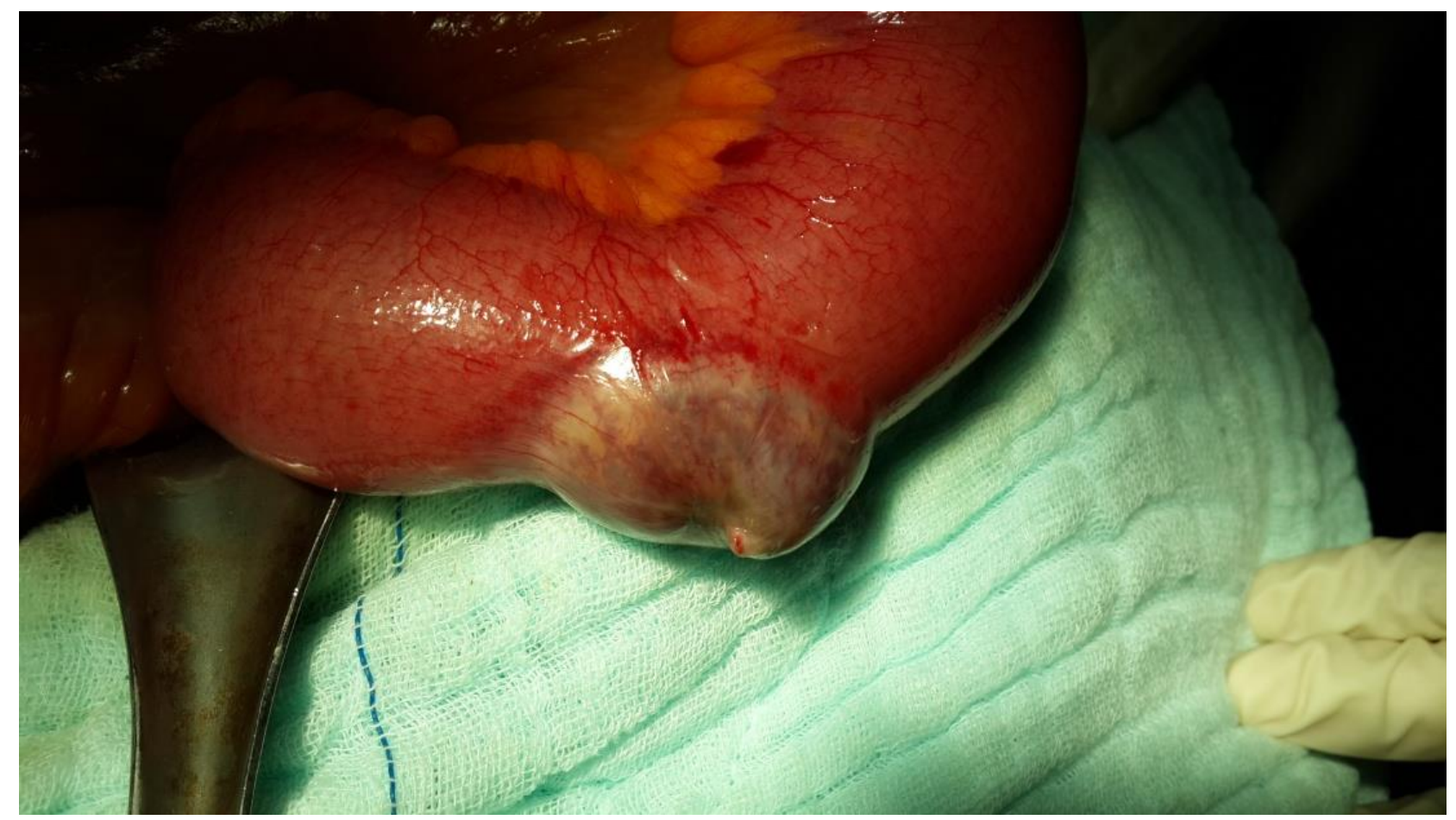

Resim 2: Nekroze olan jejunum divertikülü

\section{TARTIŞMA}

İncebarsak divertikülleri Meckel divertikülleri dışında oldukça nadirdir. Genel populasyonda \%0.06-1,9 oranında görülmektedir. Etiyolojisinde sıklıkla ince barsak duvarındaki düz kasların motor disfonksiyonu düşünülen ince barsak divertikülleri primer olabileceği gibi daha önceki operasyonlara, tüberküloza veya Crohn hastalığına sekonder olarak da gelişebilirler $(1,3)$.

Jejunoileal divertiküller $\% 60-70$ oranında asemptomatiktirler (2). Genelde bu asemptomatik divertiküller çekilen baryumlu pasaj grafilerinde veya laparotomi esnasında tesadüfen tespit edilirler. Geri kalan olgularda ise jejunoileal divertiküller bu olguda olduğu gibi akut komplikasyonlarla veya kronik semptomlarla karşımıza çıkmaktadır. Karşılaşılabilen başlıca kronik semptomlar; karın ağrısı, yemek sonrası hissedilen abdominal şişkinlik hissi, bulantı, kusma, kilo kaybı, steatore, anemi, malabsorbsiyona sekonder semptomlar ve kronik gastrointestinal kanamadır (1-2). Hastaların \%10'undan daha azında inflamasyon, hemoraji, obstruksiyon ve perforasyon gibi komplikasyonlar gelişebilir (4). Bu olguda da zaman zaman olan karın ağrısı yakınması mevcuttu.

İnce barsak divertiküllerinin akut komplikasyonları arasında ise divertikülit, masif gastrointestinal kanama ve intestinal obstruksiyon sayllabilir. İntestinal obstruksiyon, geçirilmiş divertikülit atakları sonucu gelişen adezyonlara bağlı olabileceği gibi, akut divertikülite eşlik eden inflamatuar kitleye bağlı olarak da gelişebilmektedir (5). Komplikasyonlardan önemli olanlardan biri de akut veya kronik masif hemorajidir. Bunun sebebleri ise mezenterik damarların travması, mukozal ülserasyon ve divertikülittir (1). Bu olguda tanı intestinal obstrüksiyon olup diğer komplikasyonlar görülmemiştir.

İnce barsak divertiküllerinin tanısı enteroklizis veya bilgisayarlı tomografi ile konulabilirse de bu olgudaki gibi çoğunlukla operasyon sırasında da tanı konabilmektedir (6). Tedavideki genel yaklaşım, akut vakalarda apse oluşturmuş ve perfore olmuş divertikülü içeren barsak kısmının rezeksiyonu ve uç uca anostomoz yapılmasıdır (7). Operasyondan önce tanı 
konabilirse, bu işlemler laporoskopik olarak da yapilabilmektedir (8).

Sonuç olarak; bu hastada görülen jejunoileal divertiküle bağlı gelişen intestinal obstrüksiyon, akut karın bulgusu gelişen hastalarda akılda tutulması gereken sebeplerdendir. Eğer zamanında tanı konulmazsa ciddi sonuçlara neden olabilir. $\mathrm{Bu}$ nedenle ince barsak divertikülleri, asemptomatik olsalar dahi önemsenmeli ve ayırıcı tanıda akılda bulundurulmalıdırlar.

\section{KAYNAKLAR}

1. Kouraklis G, Mantas D, Glivanou A, Kouskos E, Raftopoulos J, Karatzas G. Diverticular disease of the small bowel: Report of 27 cases. Int Surg. 2001; 86: $235-9$.

2. TsiotosGG, Farnell MB, Ilstrup DM. Nonmeckelian jejunal or ileal diverticulosis:an analysis of 112 cases. Surgery. 1994; 116: 726-31.
3. Bree E, Grammatikakis J, Christodoulakis M, Tsiftsis D. The clinical significance of acquired jejunoileal diverticula. Am J Gastroenterol. 1998; 93: $2523-7$.

4. Akhrass R, Yaffe MB, Fischer C, Ponsky J, Skuck JM. Small bowel diverticulosis: Perceptions and reality. J AM Coll Surg. 1997; 184: 383-88.

5. Freimanis MG, Ponte MP. Radiologic diagnosis of jejunal diverticulitis. Gastrointest Radiol. 1988; 13: $312-4$.

6. Patel VA, Jefferis H, Spiegelberg B, Iqbal Q, Prabhudesai A, Harris S Jejunal diverticulosis is not always a silent spectator: A report of 4 cases and review of the literature. World J Gastroenterol. 2008; 14(38): 5916-19.

7. Sibille A,Willocox R. Jejunal diverticulitis. Am J Gastroenterol 1992; 87: 655-58.

8. Cross MJ, Synder SK. Laparoscopic-directed small bowel resection for jejunal diverticulitis with perforation. J Laparoendosc Surg. 1993; 3: 47-49. doi:10.1089/lps.1993.3.47. 